\title{
Nanoencapsulation of Thymol and Eugenol with Chitosan Nanoparticles and the Effect against Ralstonia solanacearum
}

\author{
George Oluoch $^{1 *}\left(\mathbb{D}\right.$, Viviene Matiru$^{2}$, Edward George Mamati ${ }^{3}$, Moses Nyongesa $^{4}$ \\ ${ }^{1}$ Department of Molecular Biology \& Biotechnology, Pan African University, Institute for Basic Sciences, Technology and \\ Innovation (PAUSTI), Nairobi, Kenya \\ ${ }^{2}$ Department of Botany, Jomo Kenyatta University of Agriculture and Technology (JKUAT), Nairobi, Kenya \\ ${ }^{3}$ Department of Horticulture and Food Security, Jomo Kenyatta University of Agriculture and Technology (JKUAT), Nairobi, \\ Kenya \\ ${ }^{4}$ National Potato Research Centre, Kenya Agricultural and Livestock Research Organization (KALRO), Limuru, Kenya \\ Email: *George.caas@gmail.com
}

How to cite this paper: Oluoch, G., Matiru, V., Mamati, E.G. and Nyongesa, M. (2021) Nanoencapsulation of Thymol and Eugenol with Chitosan Nanoparticles and the Effect against Ralstonia solanacearum. Advances in Microbiology, 11, 723-739. https://doi.org/10.4236/aim.2021.1112052

Received: October 25, 2021

Accepted: December 11, 2021

Published: December 14, 2021

Copyright (c) 2021 by author(s) and Scientific Research Publishing Inc. This work is licensed under the Creative Commons Attribution International License (CC BY 4.0).

http://creativecommons.org/licenses/by/4.0/

(c) (i) Open Access

\begin{abstract}
Essential oils (EOs) are natural bioactive compounds with antibacterial activity against a variety of microorganisms including phytopathogens. The use of EOs and their components as viable therapeutic antibacterials is however greatly compromised by their volatile nature, hydrophobicity and instability when exposed to environmental and physiological factors. Encapsulation of these compounds in an appropriate carrier system can alleviate these challenges. This study therefore aimed at developing, characterizing and evaluating the efficacy of antibacterial potential of thymol and eugenol loaded chitosan nanoparticles (TCNPs and ECNPs) against Ralstonia solanacearum, the bacterial wilt-causing pathogen in potatoes. Synthesis of TCNP and ECNP was achieved via ionic gelation method and the prepared nanoparticles characterized by their particle size distributions, encapsulation efficiency, loading capacity (LC) and in-vitro release characteristics. Antibacterial activities of the nanoparticles were investigated using agar dilution and colony counting methods and their minimum inhibitory concentration (MIC) determined by 96-well broth micro-dilution method. Scanning electron microscope images of TCNPs and ECNPs showed that the nanoparticles were spherical in shape and were well separated with an average particle size of $590 \mathrm{~nm}$ and $555 \mathrm{~nm}$ respectively. The average size of chitosan nanoparticles alone was however $375 \mathrm{~nm}$. The encapsulation efficiency was $72.9 \%$ for TCNP (with $48.3 \%$ LC) and $71.7 \%$ for ECNP (with $49.5 \%$ LC). The release of thymol and eugenol from the microcapsules was found to be $\mathrm{pH}$ dependent with the highest re-
\end{abstract}


lease at $\mathrm{pH} 1.5$. The growth inhibition of $R$. solanacearum was $92 \%$ and $94 \%$ for TCNP and ECNPs respectively. The MIC of thymol and eugenol before encapsulation was $175 \mu \mathrm{g} / \mathrm{ml}$ and $275 \mu \mathrm{g} / \mathrm{ml}$ respectively, but this reduced significantly to $22.5 \mu \mathrm{g} / \mathrm{ml}$ and $45 \mu \mathrm{g} / \mathrm{ml}$ after encapsulation. Thus, encapsulation of thymol and eugenol in chitosan nanoparticles has shown promising potential as a bactericide alternative for $R$. solanacearum and could be useful in managing the soil borne phytopathogen.

\section{Keywords}

Essential Oil, Loading Capacity, Encapsulation Efficiency, Minimum Inhibitory Concentration, Bactericide

\section{Introduction}

Ralstonia solanacearum is an important phytopathogenic bacterium which causes bacterial wilt disease not only in potato but also in other crops in the Solanacea family, leading to significant production losses [1]. Once it invades the roots of the host plant, the pathogen aggressively colonizes the xylem vessels and eventually grows into a biofilm matrix that fills the vascular vessels leading to their obstruction and hence causing wilting [2]. Currently, bacterial wilt management is mainly achieved through cultural control methods which include the use of clean certified planting materials, growing tolerant varieties, planting in uninfested production sites and crop rotation. The current management strategies have limited efficacy and bacterial wilt continues to be an economically important problem for farmers [3]. Currently there is no known commercialized chemical management method for controlling $R$. solanacearum. Development of alternative control strategies is therefore necessary in the management of bacterial wilt.

Plant extracts contain a variety of phytochemicals with antibacterial activity which can be used for the development of novel plant protection agents. Key among the plant extract compounds are essential oils (EOs) which have been widely studied for their antibacterial activity against a variety of phytopathogens [4] [5]. Some of the EOs which have been shown to have antibacterial activity against $R$. solanacearum include clove, thyme and cinnamon [6] [7]. Studies have further shown that EOs containing phenols such as eugenol, thymol, carvacrol, citral and cinnamaldehyde as major compounds possess the highest antibacterial activity [8]. Eugenol which is a major compound of clove EOs exhibits strong antibacterial activity against a number of both gram-positive and gram-negative bacteria [9]. Thymol, a major compound of thyme EOs has also been used as medicine in many countries for many years and research has proved that it possesses antibacterial activity [10]. Previously, both thymol and eugenol have been shown to have inhibitory activity against $R$. solanacearum and are therefore potential antibacterials which can be used in the management 
of pathogen [11]. The use of these active EOs compounds as antibacterial agents against soil pathogens is limited since they are highly volatile and unstable when exposed to moisture, $\mathrm{pH}$, light and oxygen, a fact that limits their activity [12] [13]. Therefore, in order to utilize them in controlling $R$. solanacearum in potato farms, there is a necessity for an appropriate packaging and delivery system that will further enhance their efficacy.

A number of innovations and technological advancements have been applied in the agricultural field in the recent past to address food security problem. Among the novel technologies is nanotechnology in agriculture [14]. Nanotechnology has for many years have been utilized in medicine but its application in agriculture has relatively received less attention. Currently, in agriculture, research studies are exploring the use nanotechnology in controlled release of agrochemicals, plant hormone delivery, seed germination, transfer of target genes and nanosensors [15] [16]. The nanostructured systems have the potential of enhancing the efficacy of EO and their components by promoting their sustained release, reduced dosage, improved activity and minimized side effects [15] [17]. Nanotechnology therefore, has the potential to overcome the limitations that are imposed by the use of EO components as antibacterial compounds [18]. There are two mechanisms through which the use of nanoparticles can protect plants: the use of nanoparticles in providing crop protection and use of nanoparticles as carriers for existing active plant ingredients such as pesticides, fertilizers, antibacterial and antifungal compounds [15]. When used as carriers, they enhance shelf-life, improve water solubility, reduce toxicity, and boost site-specific uptake into the target microbe [15]. The nanoparticles or the nanocomposites can be applied to the plants through soaking the seeds, irrigating the roots or foliar spray [19] [20].

A number of encapsulating agents have so far been reported [21]. Among them, chitosan is the most cost effective carrier and has been used in both pharmaceutical and agricultural fields [22]. Chitosan is preferred as an ideal carrier system due to its properties including biodegradability, biocompatibility, availability, cationic charge safety, large surface area for adsorption and innate antimicrobial potential [18]. It also induces plants leaves to release hydrolytic enzymes $\beta$-glucanase and chitinase which actively contribute to the defense of plant against a variety of plant pathogens [23]. Previously, chitosan which is a deacetylated form of chitin has been extensively used to encapsulate bioactive compounds including EOs and their components such as Ocimum basilicum, Origanum vulgare and carvacrol through ionic gelation [24] [25] [26]. This study was therefore aimed at synthesizing, characterizing and evaluating thymol and eugenol loaded chitosan nanoparticles (TCNPs and ECNPs) for antibacterial efficacy against $R$. solanacearum.

\section{Material and Methods}

\subsection{Materials}

The virulent $R$. solanacearum was obtained from the Molecular Biology and 
Biotechnology Laboratory, Institute for Basic Sciences Technology and Innovation, Pan African University located in Juja (Kenya) [11]. Thymol, eugenol, Pentasodium tripolyphosphate (TPP), chitosan with low molecular weight $(75 \%$ - $85 \%$ degree of deacetylation) used as a coating material were purchased from Sigma-Aldrich, Hamburg, Germany. Tween 80, acetic acid, hydrochloric acid and ethanol (95\%) were purchased from Legacy Lab Africa.

\subsection{Preparation of Chitosan-Eugenol/Thymol Nanocomposites}

Encapsulation of eugenol and thymol in chitosan with TPP was performed using the two step oil-in-water emulsion and ionic gelation method [27]. Tween 80 was used as a surfactant and chitosan solution ( $1 \% \mathrm{w} / \mathrm{v})$ was prepared by shaking chitosan at room temperature overnight in $1 \% \mathrm{v} / \mathrm{v}$ aqueous acetic acid solution. Tween $80(336 \mu \mathrm{l})$ was added to $40 \mathrm{ml}$ of chitosan solution and the mixture stirred at $45^{\circ} \mathrm{C}$ for 2 hours forming an emulsion. Gradually, $0.5 \mathrm{~g}$ of thymol was added into the stirred mixture, and agitation carried out for $20 \mathrm{~min}$. Then, $40 \mathrm{ml}$ of $0.5 \%(\mathrm{w} / \mathrm{v})$ TPP solution was dropped slowly into the emulsion while agitating and stirring continuously at room temperature for $30 \mathrm{~min}$. Collection of the formed particles was achieved through centrifuging the formed solution at 4000 rpm for $30 \mathrm{~min}$ at $25^{\circ} \mathrm{C}$, and then cleaned by washing three times with water. The obtained wet particles were dispersed in $25 \mathrm{ml}$ of distilled water via probe sonicator for $4 \mathrm{~min}$ ( $2 \mathrm{~s}$ sonication and $1 \mathrm{~s}$ rest) in an ice bath to get a homogeneous suspension. Finally, the formed particles were freeze dried at $-65^{\circ} \mathrm{C}$ for 72 h. The dried nanoparticles (NPs) were then stored at $4^{\circ} \mathrm{C}$ until further analysis.

\subsection{Characterization of the Nanoparticles}

The morphology and the size of the nano-capsules were analyzed by scanning electron microscope (0860000 Advance Laboratory Solutions, South Africa); sample preparation followed the method described by Hosseini et al., 2013 and Fourier-transform Infrared Spectroscopy analysis (FTIR) was used to study the chemical characteristics of the nanoparticles to determine the functional groups involved in the reaction [25]. FTIR analyses for pure chitosan, thymol, eugenol together with CNPs (loaded or unloaded with thymol and eugenol) were recorded from electromagnetic spectrum range of $500-4000 \mathrm{~cm}^{-1}$ by Shimadzu FTIR-8400 (Kyoto, Japan). The samples were prepared by grinding the dried nanoparticles with potassium bromide before pressing them to form disks [28]. For each spectrum, 16 scans at a resolution of $4 \mathrm{~cm}^{-1}$ were obtained.

\subsection{Loading Capacity and Encapsulation Efficiency}

The amount of thymol and eugenol encapsulated in chitosan nanoparticles (CNPs) was determined by UV-vis spectrophotometry technique as described previously [25]. The sample was prepared by mixing $10 \mathrm{mg}$ of thymol-loaded chitosan nanoparticles (TCNPs) in $4 \mathrm{ml}$ of $2 \mathrm{M} \mathrm{HCl}$ then boiled at $95^{\circ} \mathrm{C}$ for 30 minutes. After cooling, $2 \mathrm{ml}$ of ethanol was then added to the homogenous mix- 
ture before being centrifuged at $9000 \mathrm{rpm}$ for $5 \mathrm{~min}$ at $25^{\circ} \mathrm{C}$. The procedure was repeated for eugenol-loaded-chitosan nanoparticles (ECNPs). The supernatant was then analyzed for the thymol and eugenol content using UV-vis spectrophotometry at the wavelengths of $292.5 \mathrm{~nm}$ and $295 \mathrm{~nm}$ respectively. The amount of thymol and eugenol was calculated by calibration curves of free thymol and eugenol; CNPs was similarly treated and used as a blank and standard calibration curve of both eugenol and thymol were established using five standard solutions with $0.02 \%, 0.04 \%, 0.06 \%, 0.08 \%$, and $0.10 \% \mathrm{w} / \mathrm{v}$ diluted in absolute ethanol. Each batch samples were measured in triplicate and the loading capacity (LC) along with encapsulation efficiency (EE) of the compounds were estimated from Equations (1) and (2) respectively [24].

$$
\begin{gathered}
\operatorname{EE}(\%)=\frac{\text { Weight of loaded compound }}{\text { Weight of initial compound }} \times 100 \\
\operatorname{LC}(\%)=\frac{\text { Weight of the loaded compound }}{\text { Weight of nanoparticles after freeze drying }} \times 100
\end{gathered}
$$

\subsection{In Vitro Release of Thymol and Eugenol from Chitosan Nanoparticles}

The release characteristics of thymol and eugenol from CNPs was assessed in phosphate buffer saline (PBS) at pH 1.5, 5.5 and 7.4 as described by Shetta et al., 2019 [29]. Freeze dried nanoparticles $(40 \mathrm{mg})$ were put in a dialysis bag (12,000 $14,000 \mathrm{KDa}$ ) containing $2 \mathrm{ml}$ of PBS and was then incubated in a $50 \mathrm{ml}$ tube having $15 \mathrm{ml}$ of the same release media at room temperature under gentle shaking. At every 12-hour interval, $5 \mathrm{ml}$ of release media was taken for analysis, with an addition of an equal volume of fresh release media. The total cumulative amount of thymol and eugenol (mg) in the volume of the release medium $(\mathrm{ml})$ that were encapsulated in NPs, was quantified spectrophotometrically. The release was quantified as follows:

$$
\text { Release }(\%)=[\text { Released oil/Total oil }] \times 100
$$

\subsection{Determination of Antibacterial Activities of the Nanoparticles}

The efficacy of encapsulated eugenol and thymol in CNPs against $R$. solanacearum was investigated using broth dilution and colony counting methods as described by Amro, 2017 [29]. The EOs and nano-encapsulates were first sterilized by keeping them under UV light for 2 hours while $R$. solanacearum was cultured on Casamino acid-Peptone-Glucose (CPG) broth aerobically for 24 hours at $28^{\circ} \mathrm{C}$. After overnight growth, $2.5 \mathrm{ml}$ of $R$. solanacearum culture containing $5 \%$ DMSO was taken into falcon tubes containing $5 \mathrm{mg}$ of CNPs, TCNPs, ECNPs and corresponding amounts of pure eugenol and thymol for an incubation at $28^{\circ} \mathrm{C}$ in a shaker at $250 \mathrm{rpm}$ for 12 hours. The positive control consisted of CPG broth with $R$. solanacearum in order to check the growth of the bacteria while the negative control was CPG broth alone in order to check for the sterility of the media used in the experiment. Serial dilution was then prepared from the 
falcon tubes by addition of CPG broth and then $50 \mu \mathrm{L}$ of the $7^{\text {th }}$ fold dilution was spread on the CPG agar and cultured at $28^{\circ} \mathrm{C}$ for 24 hours and the colonies quantified with the help of a colony counter. The antibacterial activity was estimated through the reduction in numbers of the bacterial colonies after introducing the sample compared with the positive control. All treatments were determined in triplicate and average value was used in determining the percentage inhibition.

$$
\text { Inhibition of } R \text {. solanacearum growth }(\%)=\frac{C-A}{C} \times 100
$$

where $C$ and $A$ are the bacterial colonies of positive control and treated plates respectively.

\subsection{Determination of Minimum Inhibitory Concentration}

The MIC of thymol, eugenol, ECNP and TCNP in relation to $R$. solanacearum were measured in triplicate by 96 -well broth micro-dilution method using resazurin dye [11]. For eugenol and thymol, the MIC was determined based on concentration ranging from 300 to $100 \mu \mathrm{g} / \mathrm{ml}(300,275,250,225,200,175,150,125$ and 100) as previously determined from a pre-experiment. However, for TCNP and ECNP it was determined using a concentration range of $720 \mu \mathrm{g} / \mathrm{ml}$ to 2.8 $\mu \mathrm{g} / \mathrm{ml}(720,360,180,90,45,22.25,11.125,5.6$ and 2.8$)$ in a CPG broth medium using a 96 well plate. The concentration range was chosen based on preliminary studies. To each well, $10 \mu \mathrm{L}$ of $R$. solanacearum $\left(10^{8} \mathrm{CFU} / \mathrm{ml}\right)$ was then added and then it was incubated at $28^{\circ} \mathrm{C}$ for 24 hours. After incubation, $20 \mu \mathrm{L}$ of resazurin solution at $0.015 \% \mathrm{~m} / \mathrm{v}$ was added per well and the results recorded after further incubation at $28^{\circ} \mathrm{C}$ for $1 \mathrm{~h}$. The lowest concentration at which no color change occurred (blue color retained) was considered as the MIC [31]. Positive control consisted of $100 \mu \mathrm{L}$ of CPG broth containing $10 \mu \mathrm{L}$ of $R$. solanacearum while the negative control contained $100 \mu \mathrm{L}$ of broth only [21]. Each experiment was carried out in duplicate and in three independent repeats.

\section{Results and Discussion}

\subsection{Morphological and Particle Size Characterizations}

The prepared CNPs, ECNPs and TCNPs were characterized using Scanning Electron Microscope, Fourier-transform Infrared Spectroscopy analysis and UV-Vis spectrophotometry. SEM images of both TCNPs and ECNPs demonstrated distinct particles with spherical shape (Figure 1). Similar results were observed when oregano EO was encapsulated in CNPs [25]. The size of polymeric nanoparticles prepared from biocompatible polymers such as chitosan had been investigated and determined to range between $10-1000 \mathrm{~nm}$ [32]. In this study, the average size of CNPs was $375 \mathrm{~nm}$ while those of TCNP and ECNP were $590 \mathrm{~nm}$ and $555 \mathrm{~nm}$ respectively (Figure 1). The smaller size of CNPs in comparison to the EO-loaded nanoparticles is due to the loading of thymol and eugenol in CNPs [25]. The nanoparticle size obtained were in the same range 

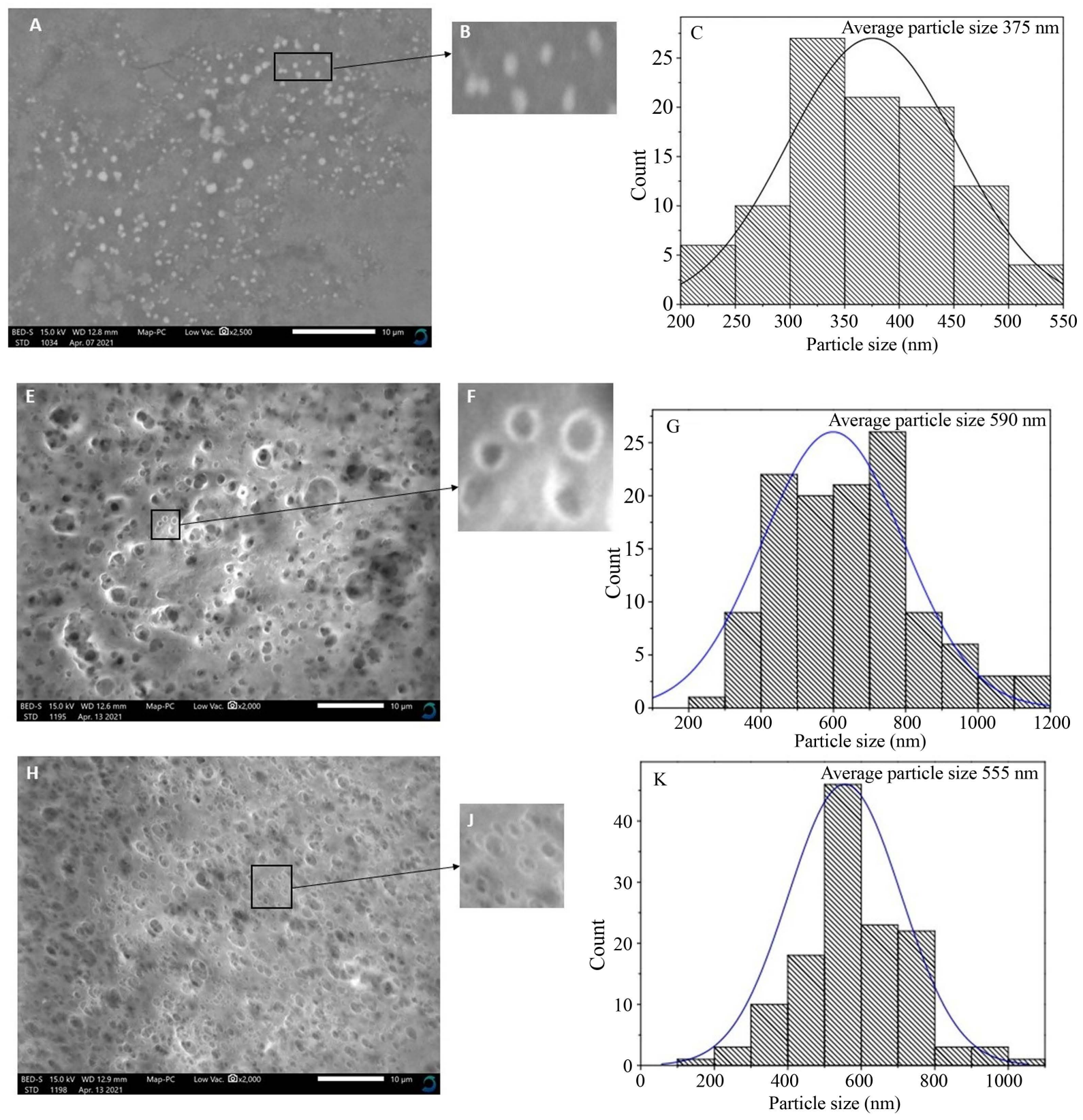

Figure 1. SEM image of CNP (A), its zoomed image (B) and particle size distribution(C); SEM image of TCNP (E), its zoomed image (F) and particle size distribution $(\mathrm{G})$; SEM image of ECNP $(\mathrm{H})$, its zoomed image $(\mathrm{J})$ and particle size distribution (K).

with a similar study which reported a range of 532.5 - $716.6 \mathrm{~nm}$ nanocapsules size when EO major component carvacrol was encapsulated in CNPs [24]. Rasaee et al., 2016 also obtained nanocapsules size range of $135-729 \mathrm{~nm}$ when leaf extract of Ocimum basilicum was encapsulated in chitosan. Morphological studies of the particles provide valuable perspective in relation to the chemical and physical factors affecting the particle structure [21].

\subsection{Fourier-Transform Infrared Spectroscopy Analysis}

FTIR spectroscopic analysis was utilized to examine the chemical characteristics 
of chitosan, CNPs, eugenol, thymol, TCNPs and ECNPs. Chitosan showed characteristic broad peak at $3408 \mathrm{~cm}^{-1}$ due to hydroxyl group and primary amine stretching. However, in CNP, this band shifted to $3423 \mathrm{~cm}^{-1}$ and became wider, indicating an enhancement in hydrogen bond due to hydrostatic interaction between amino and phosphoric groups in TPP (Figure 2) [28]. The peak at 1117 $\mathrm{cm}^{-1}$ indicated the amino group of chitosan but this peak shifted to $1121 \mathrm{~cm}^{-1}$ in CNPs. The shift is attributed to interaction between the amino group and phosphate anion in TPP signifying the formation of nanoparticles [30].

Eugenol showed characteristic peaks at $3517 \mathrm{~cm}^{-1}(\mathrm{OH}), 2843-3073 \mathrm{~cm}^{-1}$ (C-H stretching), $1513 \mathrm{~cm}^{-1}, 1608 \mathrm{~cm}^{-1}$ and $1638 \mathrm{~cm}^{-1}$ (C-C aromatic ring) (Figure 2). In comparison with the FTIR spectrum of CNP, the addition of eugenol resulted in a markedly increased intensity of the $\mathrm{C}-\mathrm{H}$ stretching peak at $2931 \mathrm{~cm}^{-1}$, indicating an increase in the content of ester groups, which might come from eugenol. This increment of $\mathrm{C}-\mathrm{H}$ stretching peak indicate a successful encapsulation of eugenol into CNP [27].

Major peaks at 3408, 2931, and $1110 \mathrm{~cm}^{-1}$ in ECNP indicated the presence of $\mathrm{N}-\mathrm{H}, \mathrm{O}-\mathrm{H}$ and $\mathrm{CH}-\mathrm{OH}$ functional groups respectively [30]. The FTIR of ECNP showed bands at 2931, 2065 and $1110 \mathrm{~cm}^{-1}$, which were absent in CNP but present in eugenol, indicating successful incorporation of eugenol in the ECNP (Figure 3). The band attendance at 3423, 3421 and $3379 \mathrm{~cm}^{-1}$ in CNP, thymol and TCNP respectively represents hydroxyl group and primary amine stretching (Figure 4). Sp3 C-H stretching appeared at $2961 \mathrm{~cm}^{-1}$ in thymol and $2960 \mathrm{~cm}^{-1}$ in TCNP and was absent in CNP which revealed the successful encapsulation of thymol with CNPs [33]. Amide stretching peaks appeared at 1597, 1591 and 1597 for CNP, thymol and TCNP respectively. A characteristic absorption peak at 1249 which is related to ether (C-O-C) bonds appeared only in thymol and

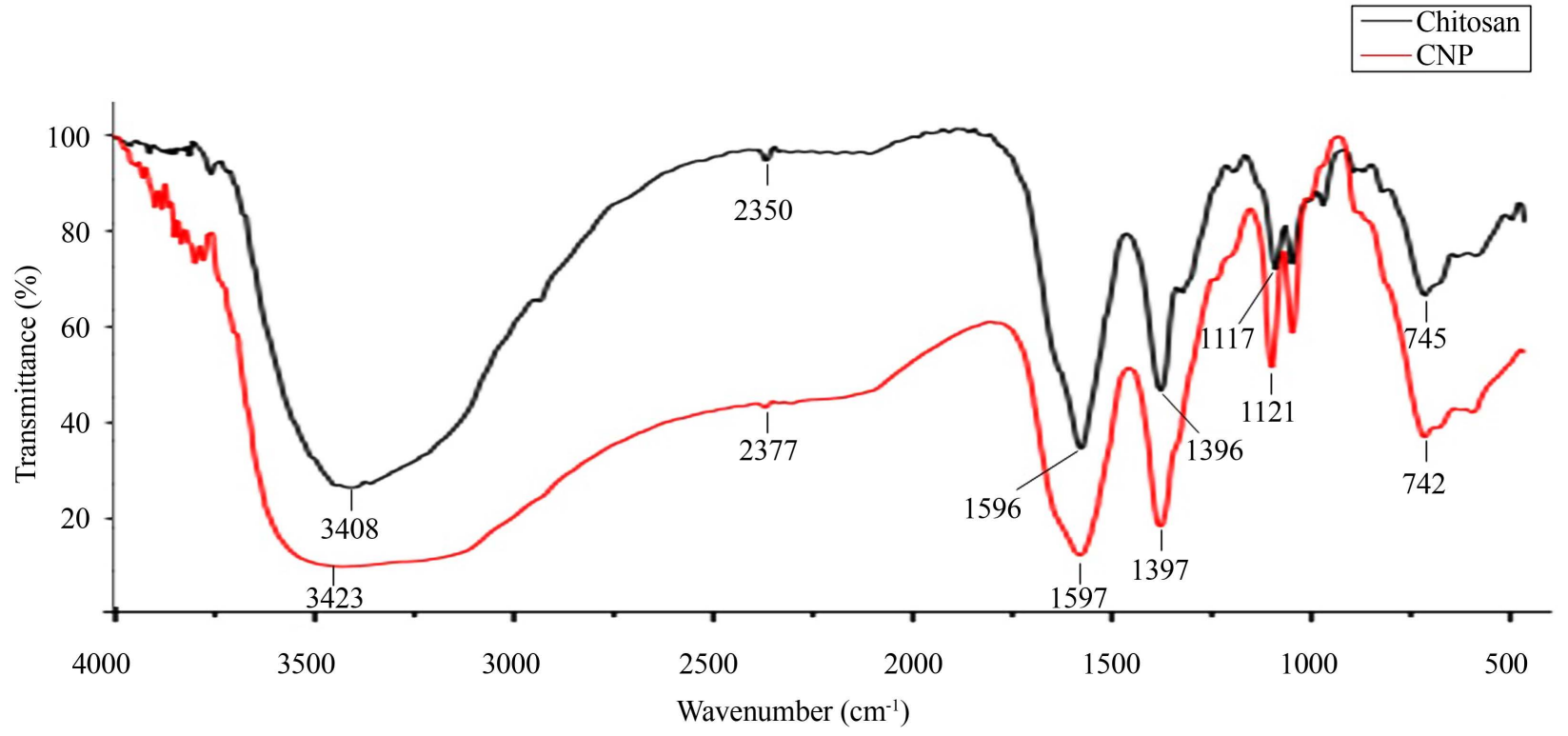

Figure 2. FTIR spectra of chitosan powder and chitosan nanoparticles (CNPs). 


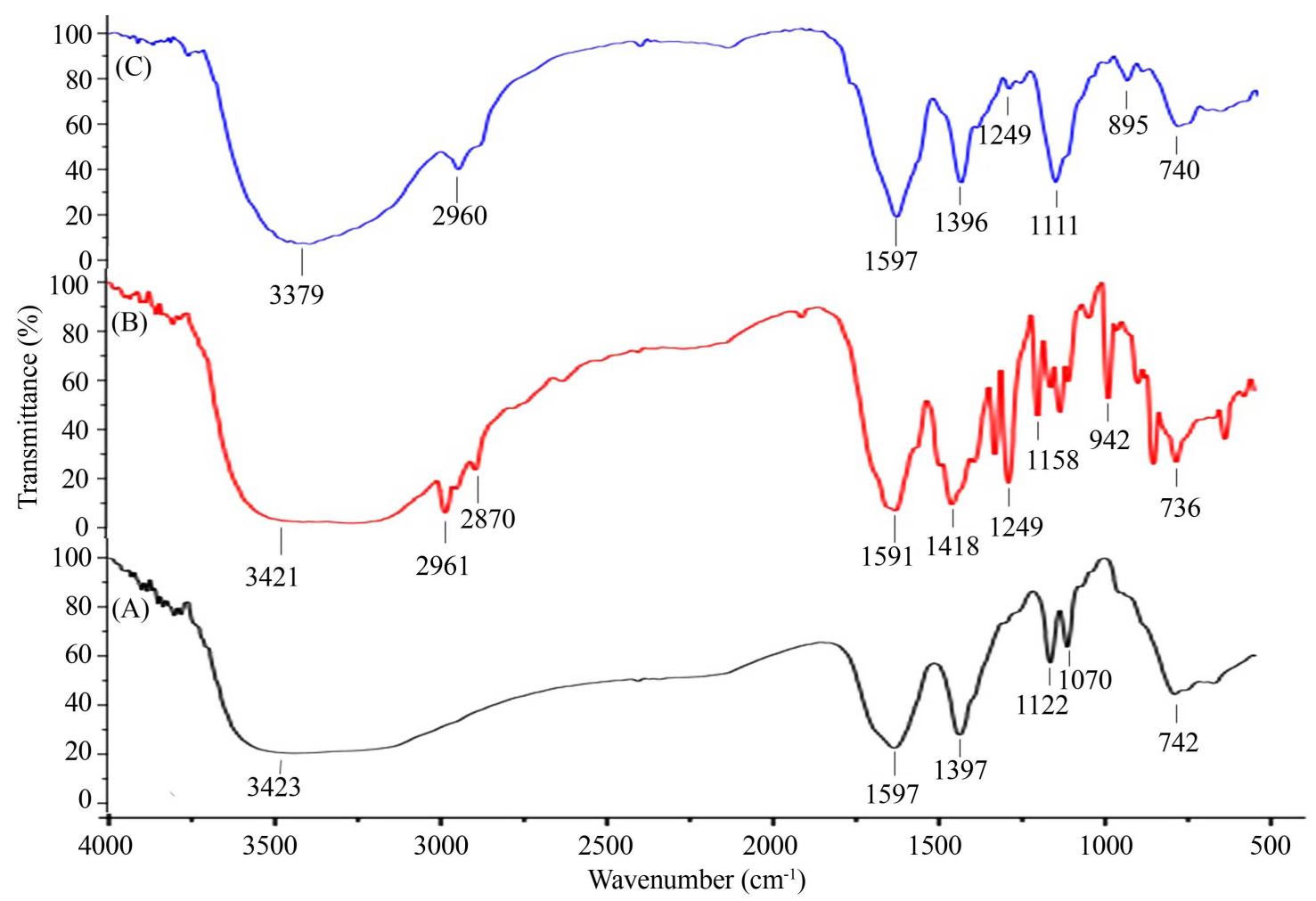

Figure 3. Fourier transform infrared (FT-IR) spectra of (A) chitosan nanoparticles (CNP), (B) eugenol, and (C) eugenol-loaded chitosan nanoparticles (ECNP).

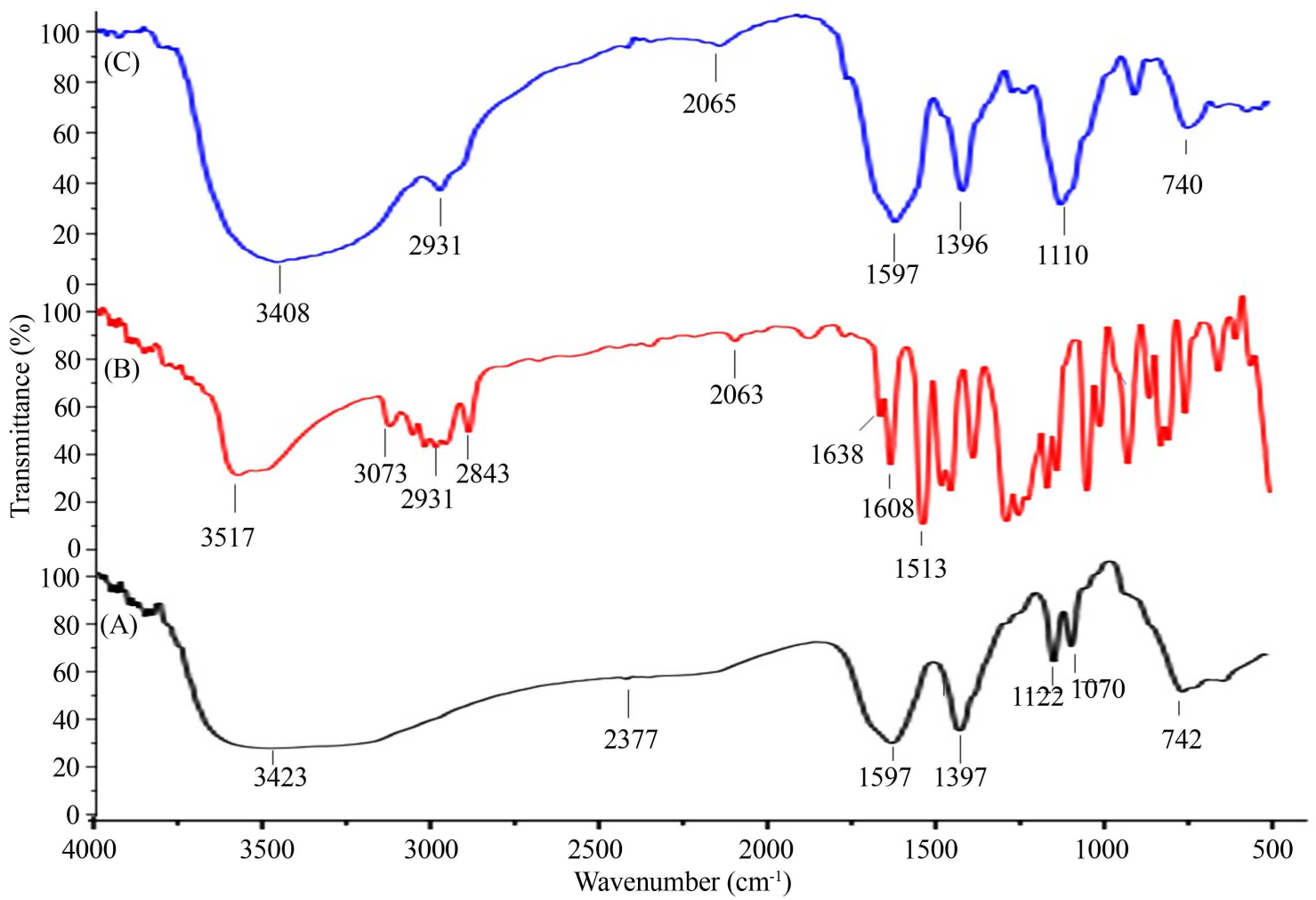

Figure 4. Fourier transform infrared (FT-IR) spectra of (A) chitosan nanoparticles (CNP), (B) Thymol, and (C) chitosan encapsulated thymol essential oil nanoparticles (TCNP). 
TCNP and was absent in CNP. Thymol and TCNP also shared a common peak at $1110 \mathrm{~cm}^{-1}$ which is related to ether (C-O-C) bonds. These FTIR results confirmed the incorporation of eugenol and thymol in the chitosan-TPP system.

\subsection{Loading Capacity and Encapsulation Efficiency}

Calibration curves for pure thymol and eugenol were constructed and used to determine LC and EE for TCNPs and ECNPs. The generated curves for thymol and eugenol had $\mathrm{R}^{2}$ of 0.996 and 0.986 respectively. The percentage amount of eugenol and thymol encapsulated in TCNP and ECNP was estimated by determining the EE and LC spectrophotometrically based on the calibration curves [24]. The EE of thymol and eugenol in TCNP and ECNP was determined as $72.9 \%$ and $71.7 \%$ while LC $\%$ was $48.3 \%$ and $49.5 \%$ respectively (Figure 5 ). These findings were in agreement with previous reports on the encapsulation of peppermint in CNPs [29] [34]. However, a higher encapsulation efficiency greater than $90 \%$ have also been reported when cardamom essential oil was encapsulated in chitosan nano-composites [18].

\subsection{In Vitro Release of Thymol and Eugenol from Chitosan Nanoparticles}

The in-vitro release study of thymol and eugenol from TCNP and ECNP was carried out for 180 hours in three different $\mathrm{pH}$ media $(1.5,5.5$ and 7.4) to confirm the successful encapsulation of the compounds and to determine the rate at which the compounds are released from the NPs [24] (Figure 6). The release profile for both eugenol and thymol could be described as a two-step biphasic process, involving an initial burst release followed by subsequent slower release [25]. In the first step (first 12 hours), there was burst release, which could be due to diffusion of the compounds adsorbed on the surface of particle and those near the surface. In the second step however, the release was relatively slow and this

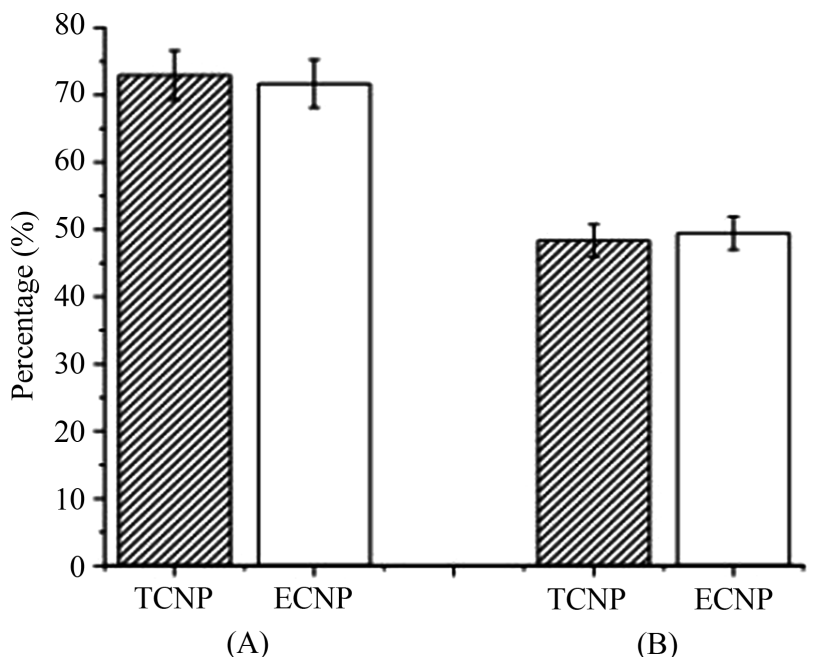

Figure 5. Encapsulation efficiency (A) and loading capacity (B) of thymol-loaded chitosan nanoparticles (TCNP) and eugenol-loaded chitosan nanoparticles (TCNP). 

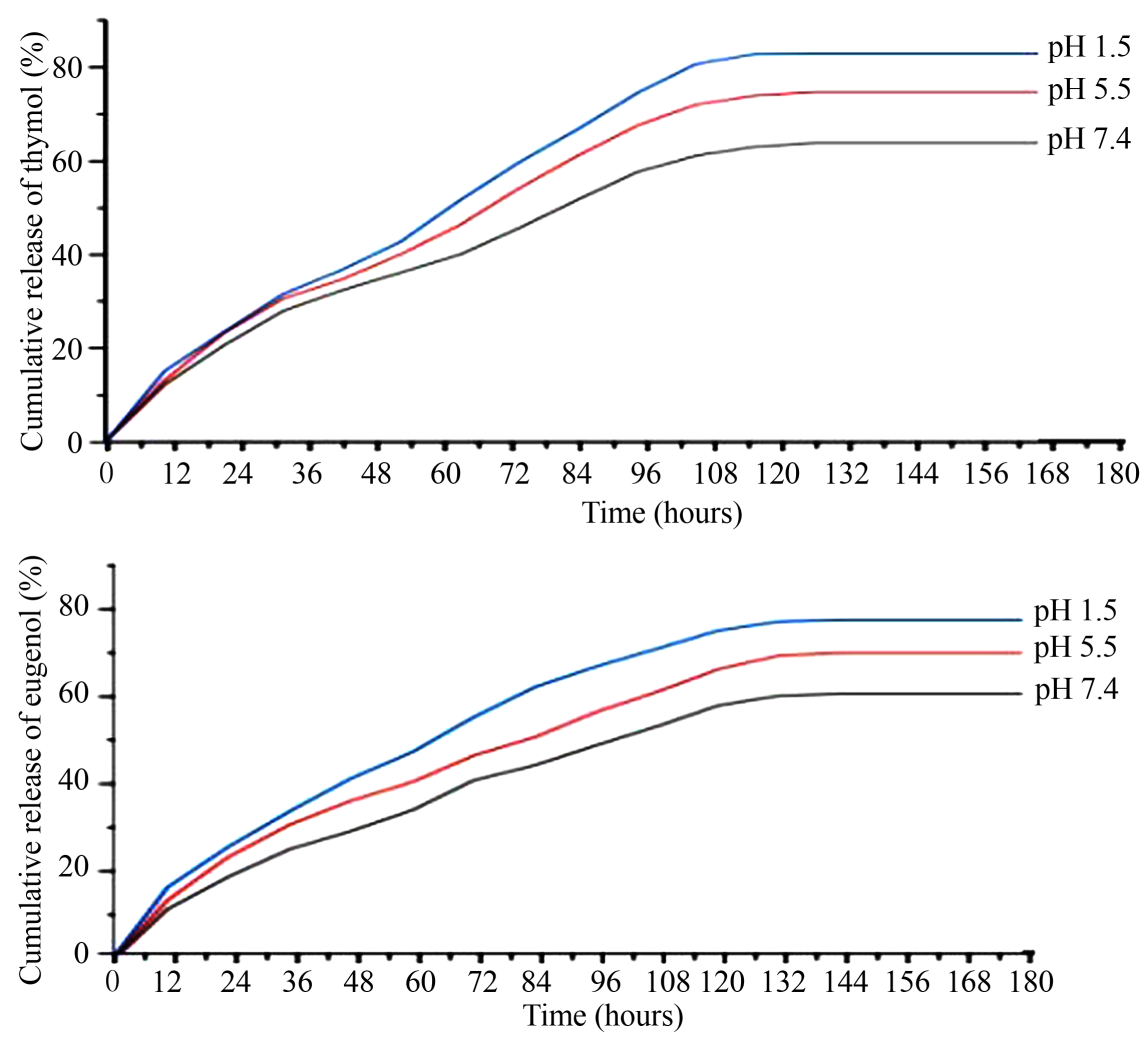

Figure 6. In vitro release profiles of thymol and eugenol from chitosan particles in different $\mathrm{pH}$ media levels.

could be attributed to the diffusion of thymol and eugenol dispersed into the polymer matrix. A similar release profile had been reported previously [24]. The release of the EO components from the microcapsules was found to be $\mathrm{pH}$ dependent. At $\mathrm{pH}$ 7.4, 5.5 and 1.5, the maximum release percentages for thymol were $63.8 \%, 74.7 \%$ and $83.0 \%$ respectively while for eugenol, the maximum release percentages were $64.1,78.1$ and $85.6 \%$ in $\mathrm{pH} 7.4,5.5$ and 1.5 respectively. The results suggest that the rate of release of thymol and eugenol from CNPs is faster in acidic solution $(\mathrm{pH}=1.5)$ than in slightly acidic $(\mathrm{pH}=5.5)$ and neutral $(\mathrm{pH}=7.4)$ respectively. In acidic media ( $\mathrm{pH} 1.5)$, both thymol and eugenol were released from CNPs very quickly, and the released contents were significantly higher than what occurs at higher $\mathrm{pH}$ media ( $\mathrm{pH}$ 7.4) which is most probably due to the swelling and partial dissolution of the NPs. The relatively higher release of the encapsulated compounds from the CNPs could be due to the partial dissolution and swelling of the TCNP and ECNP caused by ionic repulsion of protonated free amino groups on one chitosan chain with its neighboring chains [35]. It was also noted that the two compounds were not completely released from NPs because complete release needs complete degradations of CNPs [29].

\subsection{Determination of Antibacterial Activities of the Nanoparticles}

To determine the percentage mortality of $R$. solanacearum in the presence of CNPs, TCNPs and ECNPs, agar dilution and colony counting methods in CPG 
medium was used (Figure 7) as described by Shetta et al., (2019). The percentage reduction in numbers of the bacterial colonies after the treatment with TCNPs and ECNPs when compared to the colonies of positive control (CPG media with bacteria only) were used to estimate the antibacterial activity. Positive control had the highest number of $R$. solanacearum colonies which indicated a normal growth of the pathogen in CPG agar medium whereas, no colonies were observed in the negative control confirming the sterility of agar medium. In the plate containing CNPs, percentage inhibition of $80 \%$ was recorded while chitosan alone showed percentage inhibition of $44 \%$. An enhanced inhibition percentage of $92 \%$ and $94 \%$ for TCNP and ECNPs respectively when compared to the positive control was recorded (Figure 8). There was however, no

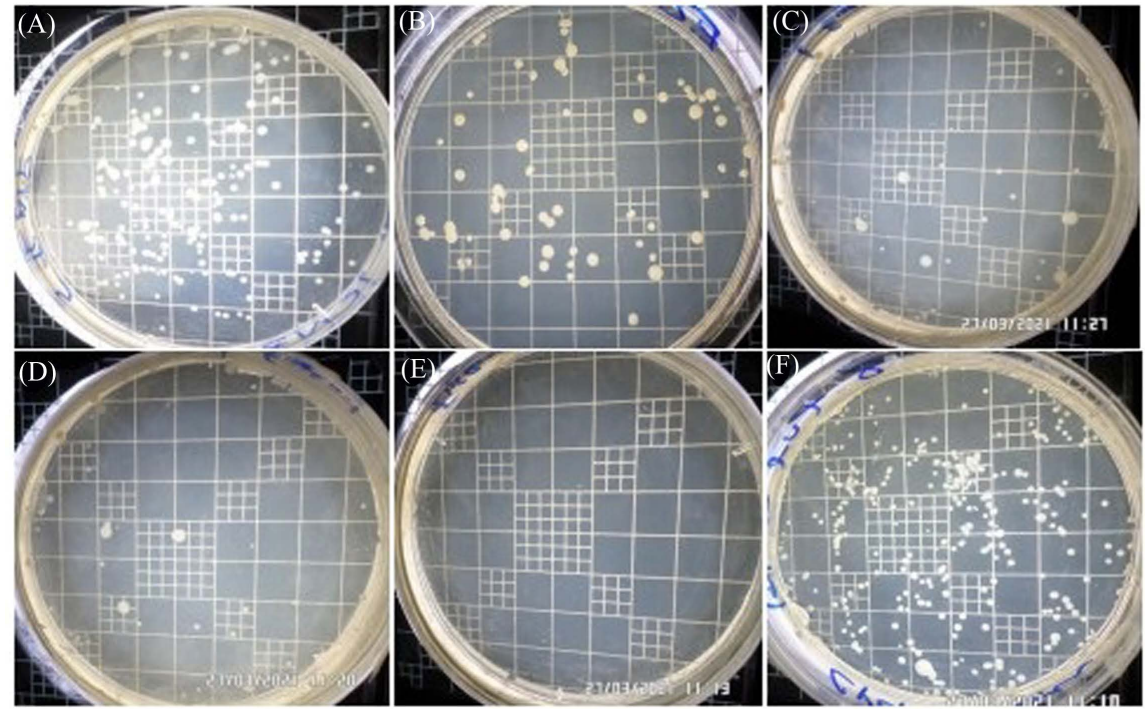

Figure 7. Bactericidal activity of Chitosan (A), CNPs (B), TCNP (C) and ECNP (D) on $R$. solanacearum in CPG media. Negative control (E) and positive control (F).

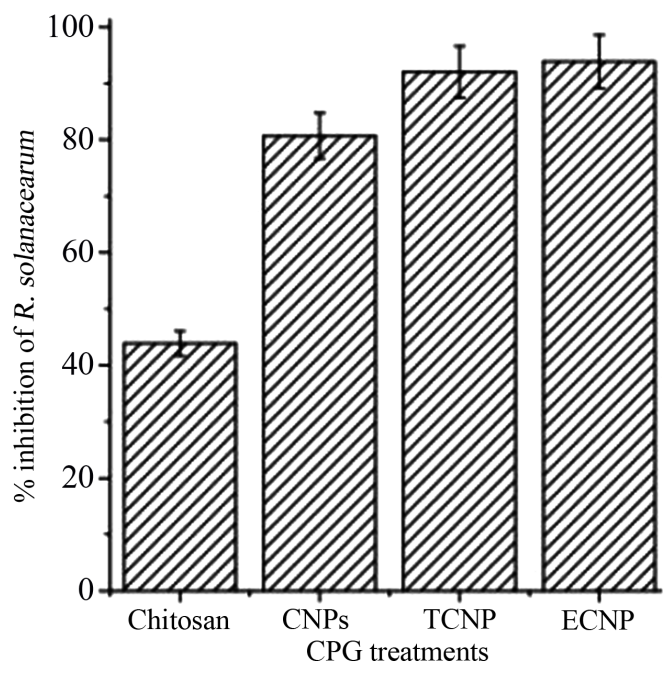

Figure 8. Inhibitory effect of chitosan, CNPs, TCNPs and ECNPs against $R$. solanacearum. 
significant difference in the rate of inhibition between TCNP and ECNP. Donsì et al., 2011 also reported similar results in which the antibacterial potential of EOs were enhanced against pathogens causing food spoilage after being encapsulated with nanoparticles [36]. In another study, Kalagatur et al., 2018 reported an enhanced antifungal activity of CNPs encapsulated with Cymbopogon martinii EO on plant pathogenic fungi Fusarium graminearum [12]. The findings are further supported by a study by Khalili et al., 2015 who reported an enhanced antifungal activity of chitosan encapsulated thyme EO nanoparticles over thyme EO during safeguarding of the tomato fruit against Aspergillus flavus [37]. The enhanced antimicrobial activity of encapsulated EOs had been linked to sustained release, improved hydrophilicity, and the better penetration resulting from small size of the nanocapsules [38].

\subsection{Determination of the Minimum Inhibitory Concentration}

Using the minimum inhibitory concentration assay, thymol, eugenol, TCNPs and ECNPs were compared for the antimicrobial efficacy of the EO against $R$. solanacearum. Before encapsulation, the MIC of thymol and eugenol was determined as $175 \mu \mathrm{g} / \mathrm{ml}$ and $275 \mu \mathrm{g} / \mathrm{ml}$ respectively (Table 1 ). However, after encapsulation with CNPs, the MIC of thymol and eugenol against $R$. solanacearum reduced significantly to $22.5 \mu \mathrm{g} / \mathrm{ml}$ and $45 \mu \mathrm{g} / \mathrm{ml}$ respectively (Table 2). In a study by Van Vuuren et al., 2010, the MIC values of Melaleuca alternifolia EO ranged from $250 \mu \mathrm{g} / \mathrm{ml}$ against $C$. albicans to $2000 \mu \mathrm{g} / \mathrm{ml}$ against $E$. coli and $S$. aureus [39]. After encapsulation however, the MIC was lowered to values between 17 and $34 \mu \mathrm{g} / \mathrm{ml}$ against all the pathogens. The reduction in MIC was

Table 1. Inhibitory levels of thymol and eugenol against $R$. solanacearum.

\begin{tabular}{cccccccccccccc}
\hline & \multicolumn{10}{c}{ Concentration $(\mu \mathrm{g} / \mathrm{ml})$} \\
\cline { 2 - 10 } Compounds & 300 & 275 & 250 & 225 & 200 & 175 & 150 & 125 & 100 & $+\mathrm{ve}$ & $-\mathrm{ve}$ \\
\hline Thymol & + & + & + & + & + & + & - & - & - & + & - \\
Eugenol & + & + & - & - & - & - & - & - & - & + & - \\
\hline
\end{tabular}

Inhibited; (+): not inhibited; (-): Positive control (broth $+R$. solanacearum); (+ve): Negative control (broth only); (-ve).

Table 2. Inhibitory levels of TCNP and ECNP against $R$. solanacearum.

\begin{tabular}{cccccccccccccc}
\hline & \multicolumn{10}{c}{ Compounds } & \multicolumn{10}{c}{ Concentration $(\mu \mathrm{g} / \mathrm{ml})$} \\
\cline { 2 - 11 } & 720 & 360 & 180 & 90 & 45 & 22.5 & 11.3 & 5.6 & 2.8 & $+\mathrm{ve}$ & $-\mathrm{ve}$ \\
\hline $\mathrm{TCNP}$ & + & + & + & + & + & + & - & - & - & + & - \\
$\mathrm{ECNP}$ & + & + & + & + & + & - & - & - & - & + & - \\
$\mathrm{CNP}$ & + & + & - & - & - & - & - & - & - & + & - \\
\hline
\end{tabular}

Inhibited; (+): not inhibited; (-): Positive control (broth $+R$. solanacearum); (+ve): Negative control (broth only); (-ve). 
attributed to the persistence of antibacterial activity due to the sustained release of compounds [40]. The reduction MIC may also be due to synergistic activity between EO compounds and CNPs [39].

\section{Conclusion}

Nanotechnology is one of the latest technological advancements, that is the most promising in agriculture. In the present study, thymol and eugenol were successfully encapsulated in CNPs and their antibacterial activity tested against $R$. solanacearum in vitro. Successful encapsulation of the compounds in CNPs was confirmed by SEM, FTIR and UV-Vis spectroscopy. SEM images of CNPs, TCNPs and ECNPs showed that the nanoparticles had average sizes of $375 \mathrm{~nm}$, $590 \mathrm{~nm}$ and $555 \mathrm{~nm}$ consecutively. The encapsulation of thymol and eugenol in CNPs has been demonstrated to beneficial from different perspectives, including their protection from the surrounding medium, enhanced antibacterial activity and their controlled release from the nanocapsules. TCNP and ECNP were observed to be highly effective in controlling $R$. solanacearum in vitro with enhanced growth inhibition percentages of $92 \%$ and $94 \%$ for TCNP and ECNPs consecutively when compared to the positive control. The MIC of the encapsulated eugenol and thymol was also found to be much lower than those obtained for thymol and eugenol. This study has therefore demonstrated that encapsulation of thymol and eugenol in CNPs could protect them from degradation and enhance their antimicrobial efficacy against $R$. solanacearum. TCNP and ECNP therefore have a great potential to be used as a bactericide for managing the soil borne phytopathogen. There is need however, for an in vivo test to confirm their activity against the bacterial wilt causing soil borne pathogen.

\section{Acknowledgements}

The authors acknowledge the African Union Commission through the Pan African University Institute for Basic Sciences, Technology, and Innovation for providing the research materials and funds.

\section{Conflicts of Interest}

The authors declare no conflicts of interest regarding the publication of this paper.

\section{References}

[1] Vu, T.T., Choi, G.J. and Kim, J.C. (2017) Plant-Derived Antibacterial Metabolites Suppressing Tomato Bacterial Wilt Caused by Ralstonia solanacearum. Research in Plant Disease, 23, 89-98. https://doi.org/10.5423/RPD.2017.23.2.89

[2] Lowe-Power, T.M., Khokhani, D. and Allen, C. (2018) How Ralstonia solanacearum Exploits and Thrives in the Flowing Plant Xylem Environment. Trends in Microbiology, 26, 929-942. https://doi.org/10.1016/j.tim.2018.06.002

[3] Pradhanang, P.M., Momol, M.T., Olson, S.M. and Jones, J.B. (2003) Effects of Plant Essential Oils on Ralstonia solanacearum Population Density and Bacterial wilt In- 
cidence in Tomato. Plant Disease, 87, 423-427. https://doi.org/10.1094/PDIS.2003.87.4.423

[4] Puškárová, A., Bučková, M., Kraková, L., Pangallo, D. and Kozics, K. (2017) The Antibacterial and Antifungal Activity of Six Essential Oils and Their Cyto/Genotoxicity to Human HEL 12469 Cells. Scientific Reports, 7, Article No. 8211. https://doi.org/10.1038/s41598-017-08673-9

[5] Ozdemir, E. and Gozel, U. (2018) Nematicidal Activities of Essential Oils against Meloidogyne incognita on Tomato Plant. Fresenius Environmental Bulletin, 27, 4511-4517.

[6] Lee, Y.H., Choi, C.W., Kim, S.H., Yun, J.G., Chang, S.W., Kim, Y.S. and Hong, J.K. (2012) Chemical Pesticides and Plant Essential Oils for Disease Control of Tomato Bacterial Wilt. Plant Pathology Journal, 28, 32-39.

https://doi.org/10.5423/PPJ.OA.10.2011.0200

[7] Huang, Q. and Lakshman, D. K. (2010) Effect of Clove Oil on Plant Pathogenic Bacteria and Bacterial Wilt of Tomato and Geranium. Journal of Plant Pathology, 92, 701-707.

[8] Bassolé, I.H.N. and Juliani, H.R. (2012) Essential Oils in Combination and Their Antimicrobial Properties. Molecules, 17, 3989-4006.

https://doi.org/10.3390/molecules17043989

[9] Charan Raja, M.R., Srinivasan, V., Selvaraj, S. and Mahapatra, S.K. (2015) Versatile and Synergistic Potential of Eugenol: A Review. Pharmaceutica Analytica Actaa, 6, Article No. 367. https://doi.org/10.4172/2153-2435.1000367

[10] Nagoor Meeran, M.F., Javed, H., Taee, H.A, Azimullah, S. and Ojha, S.K. (2017) Pharmacological Properties and Molecular Mechanisms of Thymol: Prospects for Its Therapeutic Potential and Pharmaceutical Development. Frontiers in Pharmacology, 8, Article No. 380. https://doi.org/10.3389/fphar.2017.00380

[11] Oluoch, G., Mamati, E.G., Matiru, V. and Nyongesa, M. (2021) Efficacy of Thymol and Eugenol against Bacterial Wilt Bacterium Ralstonia solanacearum. African Journal of Biotechnology, 20, 256-265.

[12] Kalagatur, N.K., Nirmal, O.S., Sundararaj, N. and Mudili, V. (2018) Antifungal Activity of Chitosan Nanoparticles Encapsulated with Cymbopogon martinii Essential Oil on Plant Pathogenic fungi Fusarium graminearum. Frontiers in Pharmacology, 9, Article No. 610. https://doi.org/10.3389/fphar.2018.00610

[13] Kit-Kay, M., Masnah, B.K., Sunday, B.A., Raghavendra, S., Yew-Beng, K., Kavitha, M., Madhu, K.B., Sazali, H.A. and Mallikarjuna, R.P. (2019) A Comprehensive Review on Eugenol's Antimicrobial Properties and Industry Applications: A Transformation from Ethnomedicine to Industry. Pharmacognosy Reviews, 13, 1-9. https://doi.org/10.4103/phrev.phrev $46 \quad 18$

[14] Das, A. and Bimal, D. (2016) Nanotechnology a Potential Tool to Mitigate Abiotic Stress in Crop Plants. In: De Oliveira, A., Ed., Abiotic and Biotic Stress in Plants, IntechOpen, London, 1-8.

[15] Worrall, E.A., Hamid, A., Mody, K.T., Mitter, N. and Pappu, H.R. (2018) Nanotechnology for Plant Disease Management. Agronomy, 8, Article No. 285. https://doi.org/10.3390/agronomy8120285

[16] Shang, Y., Kamrul, M., Ahammed, G.J., Li, M., Yin, H. and Zhou, J. (2019) Applications of Nanotechnology in Plant Growth and Crop Protection: A Review. Molecules, 24, Article No. 2558. https://doi.org/10.3390/molecules24142558

[17] Bonifácio, B.V., Silva, P.B., Ramos, M.A. Dos S., Negri, K.M. S., Bauab, T.M. and Chorilli, M. (2014) Nanotechnology-Based Drug Delivery Systems and Herbal Me- 
dicines: A Review. International Journal of Nanomedicine, 4, 1-15. https://doi.org/10.2147/IJN.S52634

[18] Jamil, B., Abbasi, R., Abbasi, S., Imran, M., Khan, S.U., Ihsan, A., Javed, S. and Bokhari, H. (2016) Encapsulation of Cardamom Essential Oil in Chitosan Nano-Composites: In-Vitro Efficacy on Antibiotic-Resistant Bacterial Pathogens and Cytotoxicity Studies. Frontiers in Microbiology, 7, Article No. 1580. https://doi.org/10.3389/fmicb.2016.01580

[19] Chen, J., Mao, S., Xu, Z. and Ding, W. (2019) Various Antibacterial Mechanisms of Biosynthesized Copper Oxide Nanoparticles against Soilborne Ralstonia solanacearum. RSC Advances, 9, 3788-3799. https://doi.org/10.1039/C8RA09186B

[20] Algam, S.A.E., Xie, G., Li, B., Yu, S., Su, T. and Larsen, J. (2010) Effects of Paenibacillus Strains and Chitosan on Plant Growth Promotion and Control of Ralstonia Wilt in Tomato. Journal of Plant Pathology, 92, 593-600.

[21] Hasani, M. and Hasani, S. (2018) Nano-Encapsulation of Thyme Essential Oil in Chitosan-Arabic Gum System: Evaluation of Its Antioxidant and Antimicrobial Properties. Trends in Phytochemical Research, 2, 75-82.

[22] Dennis, G., Harrison, W., Agnes, K. and Erastus, G. (2016) Effect of Biological Control Antagonists Adsorbed on Chitosan Immobilized Silica Nanocomposite on Ralstonia solanacearum and Growth of Tomato Seedlings. Advances in Research, 6, 1-23. https://doi.org/10.9734/AIR/2016/22742

[23] Mandal, S., Kar, I., Mukherjee, A. K. and Acharya, P. (2013) Elicitor-Induced Defense Responses in Solanum lycopersicum against Ralstonia solanacearum. The Scientific World Journal, 2013, Article ID: 561056. https://doi.org/10.1155/2013/561056

[24] Keawchaoon, L. and Yoksan, R. (2011) Preparation, Characterization and in Vitro Release Study of Carvacrol-Loaded Chitosan Nanoparticles. Colloids and Surfaces B: Biointerfaces, 84, 163-171. https://doi.org/10.1016/j.colsurfb.2010.12.031

[25] Hosseini, seyed fakhreddin, Zandi, M., Rezaei, M. and Farahmand, F. (2013) Two-Step Method for Encapsulation of Oregano Essential Oil in Chitosan Nanoparticles: Preparation, Characterization and in Vitro Release Study. Carbohydrate Polymers, 95, 50-56. https://doi.org/10.1016/j.carbpol.2013.02.031

[26] Rasaee, I., Ghannadnia, M. and Honari, H. (2016) Antibacterial Properties of Biologically Formed Chitosan Nanoparticles Using Aqueous Leaf Extract of Ocimum basilicum. Mashhad University of Medical Sciences, 3, 240-247.

[27] Woranuch, S. and Yoksan, R. (2013) Eugenol-Loaded Chitosan Nanoparticles: I. Thermal Stability Improvement of Eugenol through Encapsulation. Carbohydrate Polymers, 96, 578-585. https://doi.org/10.1016/j.carbpol.2012.08.117

[28] El-Aziz, A.R.M. A., Al-Othman, M.R., Mahmoud, M.A., Shehata, S.M. and Abdelazim, N.S. (2018) Chitosan Nanoparticles as a Carrier for Mentha longifolia Extract: Synthesis, Characterization and Antifungal Activity. Current Science, 114, 2116-2122. https://doi.org/10.18520/cs/v114/i10/2116-2122

[29] Shetta, A., Kegere, J. and Mamdouh, W. (2019) Comparative Study of Encapsulated Peppermint and Green Tea Essential Oils in Chitosan Nanoparticles: Encapsulation, Thermal Stability, in-Vitro Release, Antioxidant and Antibacterial Activities. International Journal of Biological Macromolecules, 126, 731-742. https://doi.org/10.1016/j.ijbiomac.2018.12.161

[30] Natrajan, D., Srinivasan, S., Sundar, K. and Ravindran, A. (2015) Formulation of Essential Oil-Loaded Chitosan-Alginate Nanocapsules. Journal of Food and Drug Analysis, 23, 560-568. https://doi.org/10.1016/j.jfda.2015.01.001 
[31] Sarker, S.D., Nahar, L. and Kumarasamy, Y. (2007) Microtitre Plate-Based Antibacterial Assay Incorporating Resazurin as an Indicator of Cell Growth, and Its Application in the in Vitro Antibacterial Screening of Phytochemicals. Methods, 42, 321-324. https://doi.org/10.1016/j.ymeth.2007.01.006

[32] Khanmohammadi, M., Elmizadeh, H. and Ghasemi, K. (2015) Investigation of Size and Morphology of Chitosan Nanoparticles Used in Drug Delivery System Employing Chemometric Technique. Iranian Journal of Pharmaceutical Research, 14, 665-675.

[33] Shetta, A.A.A. (2017) Encapsulation of Essential Oils in Chitosan Nanoparticle formulations and Investigation on their Antioxidant and Antibacterial Properties. Master's Theses, American University in Cairo, New Cairo.

[34] Deka, C., Deka, D., Bora, M.M., Jha, D.K. and Kakati, D. K. (2016) Synthesis of Peppermint Oil-Loaded Chitosan/Alginate Polyelectrolyte Complexes and Study of Their Antibacterial Activity. Journal of Drug Delivery Science and Technology, 35, 314-322. https://doi.org/10.1016/j.jddst.2016.08.007

[35] Zhang, H., Mardyani, S., Chan, W.C.W. and Kumacheva, E. (2006) Design of Biocompatible Chitosan Microgels for Targeted $\mathrm{pH}$-Mediated Intracellular Release of Cancer Therapeutics. Biomacromolecules, 7, 1568-1572.

https://doi.org/10.1021/bm050912z

[36] Donsì, F., Annunziata, M., Sessa, M. and Ferrari, G. (2011) Nanoencapsulation of Essential Oils to Enhance Their Antimicrobial Activity in Foods. LWT-Food Science and Technology, 44, 1908-1914. https://doi.org/10.1016/j.lwt.2011.03.003

[37] Khalili, S. T., Mohsenifar, A., Beyki, M., Zhaveh, S., Rahmani-Cherati, T., Abdollahi, A., Bayat, M. and Tabatabaei, M. (2015) Encapsulation of Thyme Essential Oils in Chitosan-Benzoic Acid Nanogel with Enhanced Antimicrobial Activity against Aspergillus flavus. LWT-Food Science and Technology, 60, 502-508. https://doi.org/10.1016/j.lwt.2014.07.054

[38] Esfandyari-Manesh, M., Ghaedi, Z., Asemi, M., Khanavi, M., Manayi, A., Jamalifar, H., Atyabi, F. and Dinarvand, R. (2013) Study of Antimicrobial Activity of Anethole and Carvone Loaded PLGA Nanoparticles. Journal of Pharmacy Research, 7, 290-295. https://doi.org/10.1016/j.jopr.2013.04.019

[39] Van Vuuren, S. F., Du Toit, L. C., Parry, A., Pillay, V. and Choonara, Y. E. (2010) Encapsulation of Essential Oils within a Polymeric Liposomal Formulation for Enhancement of Antimicrobial Efficacy. Natural Product Communications, 5, 1401-1408. https://doi.org/10.1177/1934578X1000500912

[40] Kokina, M., Salevic, A., Kaluševic, A., Levic, S., Pantic, M., Dejan Pljevljakušic, Šavikin, K., Shamtsyan, M., Nikšic, M. and Nedovic, V. (2019) Characterization, Antioxidant and Antibacterial Activity of Essential Oils and Their Encapsulation into Biodegradable Material Followed by Freeze Drying. Food Technology and Biotechnology, 57, 282-289. https://doi.org/10.17113/ftb.57.02.19.5957 